\title{
城市公交大客车车身结构分析与优化研究
}

金宏宇

浙江吉利新能源商用车集团有限公司，浙江 杭州 311228

[摘要] 文章以城市公交客车为研究对象，对车身结构、座椅强度进行了分析，在此基础上，结合实际情况提出了相应的优化 策略, 希望可以在某些方面给人以启发, 为客车行业的发展注入动力, 使人们的日常出行变得更加便利, 另外, 这样做还可 以使乘客的人身安全得到保障。

[关键词]公交大客车; 结构分析; 车身优化

DOI: $10.33142 /$ ec.v3i4.1762

中图分类号: U462.2

文献标识码：A

\section{Analysis and Optimization of Body Structure of City Bus}

JIN Hongyu

Zhejiang Geely New Energy Commercial Vehicle Group Co., Ltd., Hangzhou, Zhejiang, 311228, China

\begin{abstract}
Based on analysis of the body structure and seat strength of city bus, this paper puts forward the corresponding optimization strategy in combination with the actual situation, hoping to inspire people in some aspects, inject power into the development of the bus industry and make people's daily travel more convenient. In addition, it can also ensure safety of passengers.
\end{abstract}

Keywords: bus; structure analysis; body optimization

\section{引言}

不断增加的客车产量和保有量, 致使行业竞争变得更加激烈, 要想占据更大的市场份额, 将作为城市公交的客车 的价值进行充分发挥, 对车身结构进行优化就显得很有必要, 作为直接接触人体的零部件, 座椅强度、安全性的重要 性不言而喻, 由此可见，结合客车特点，确定座椅的优化方案，具有突出的现实意义。

\section{1 公交客车座椅强度分析}

公交客车座椅强度分析, 被视为对座椅进行优化的首要环节。正常情况下, 座椅应达到以下效果：其一，使乘客受 限疲劳减轻, 对复杂载荷加以承受; 其二, 联合扶手、靠背等零部件, 完成乘客的定位, 保证即使有事故发生, 乘客的 碰撞强度也可以得到缓解 ${ }^{[1]}$ 。由此可见, 座椅既需要具备科学的结构形式、几何参数及体压分布, 还应当具有缓冲、应对 冲击和消振的作用。无论是停车还是行车状态下, 公交客车均承受着复杂的载荷, 仅仅凭借模拟演示、仿真实验所获得 数据, 其准确性无法得到保证, 因此, 要想高效完成结构分析和优化任务, 工作人员应对现有手段进行整合, 通过对参 数进行折算的方式, 将座椅的承载能力转化为极限载荷, 下文所展开研究均以此为前提, 有效性能够得到保障。

\section{2 公交客车结构分析及优化}

\section{1 强度分析}

作为主要出行工具, 客车主要指的是对乘客、随身行李进行载运的商用车, 其 优势体现在两个方面, 分别是占地面积小、载客量较大。在底盘、发动机、座椅等 构成客车的零部件中, 人们关注的焦点, 始终集中在座椅上, 围绕其展开的研究, 正在变得深入且具体。参照国际标准, 对客车座椅强度实验的方案进行制定。在施 加载荷的过程中, 工作人员应遵循以下规定: 所施加载荷应为座椅质量的 20 倍, 换 句话说, 座椅应有承受 20 倍载荷的强度, 另外, 座椅变形范围应得到严格控制, 车 体、座椅分离的情况, 应得到有效解决。美国、欧洲对公交客车所提出要求, 基本 与上文相同, 若座椅可调, 即使遭受座椅质量 20 倍的冲击, 调节装置所处位置也不 应出现变化, 当然, 是否需要保有调节功能并无明确规定, 这点需要引起重视。座 椅靠背强度应满足以下要求: 如果遇到追尾、碰撞等情况, 乘客身体滑动范围、回

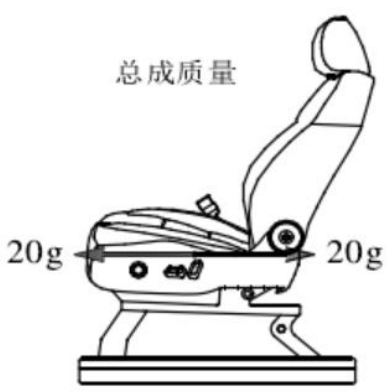

图 1 公交客车座椅强度加载图 
弹强度均应得到满足。工作人员应着重考虑乘客的胸部倾角、颈椎倾角和躯基准线，如图 $1^{[2]}$ 。

从人机工程学的角度来说, 要想保证乘客坐姿正确、脊柱形态正常, 公交客车座椅靠背的倾角, 应当较体腿夹角 略小, 一般来说, 以 $100^{\circ}$ 为最佳, 此时, 人体给座椅所施加强度负荷相对均匀, 座椅也更加安全。在进行实验的过程 中, 工作人员应重点观察骨架、固定点、调节系统、位移系统是否失效, 虽然不会导致伤害程度被增加的变形、断裂 是允许出现在实验中的, 但是, 工作人员应保证变形、断裂部位, 对规定载荷有承受能力。如果公交客车采用的是整 体式座椅, 工作人员应在垂直于参考线的平面上, 在与基准点相距 $500 \mathrm{~mm}$ 处, 对 $1000 \mathrm{~N}$ 负荷进行恒定施加, 在加载过 程中，利用 MPC 点连接附近区域，保证负荷力能够得到均匀分布。

\section{2 CAE 分析}

利用计算机进行辅助分析的流程如下: 首先, 对所建数模进行导入; 其次, 利用样品对零部件性能进行模拟, 减 少重复所浪费时间, 降低开发成本; 最后, 正式投入使用。综合有限元理论、静力学理论可知, 不同工况下, 公交客 车座椅所表现出的力学性能, 往往存在显著差异, 工作人员应重点优化座椅靠背和固件, 以优化结果为依据, 对内板、 管结构加以设计, 保证实际需求得到满足。除此之外, 要想使企业所提出设计目标得到满足, 待优化环节告一段落, 工作人员可视情况对铝合金、高强度钢等材料加以应用，分别制定不同的优化方案，在计算机的辅助下，完成对优化 效果的对比, 得出最终结论。

\section{3 载荷实验}

作为联系公交客车和乘客的核心部件, 座椅对乘客的乘车体验起决定作用。国家、企业均针对座椅性能制定了一 系列要求, 实验设备、流程均已趋于完善, 这为行业水平得到提高、乘客安全得到保障奠定了基础。分析座椅有限元 仿真可知, 若载荷被集中施加, 应力值多存在于调角器、座盆侧板连接等部分, 即便应力值并未达到屈服极限, 座椅 结构仍旧会被载荷作用影响, 导致金属材料失效时间大幅提前, 由此而引发的问题, 主要是座椅结构被破坏, 另外, 处于行驶状态下的公交客车, 往往要承受路面所传递载荷, 作为交变载荷, 路面所传递载荷带来的影响, 主要体现在 破坏结构、降低安全性的方面。

循环载荷实验选用 St12 骨架, Q235 调角器横管, 08A1 结构材料, 每分钟向座椅靠背施加 550N 循环载荷 30 次, 所得曲线如图 $2^{[3]}$ 。实验结果表明, 连接调角器、座盆侧板的部位, 其使用寿命普遍较短, 只有优化调角器、座盆侧板 的材料, 增加构件厚度, 使二者具备更加突出的强度, 才能降低变形、疲劳破坏等问题出现的几率, 座椅强度、客车 安全性, 自然会得到保障。

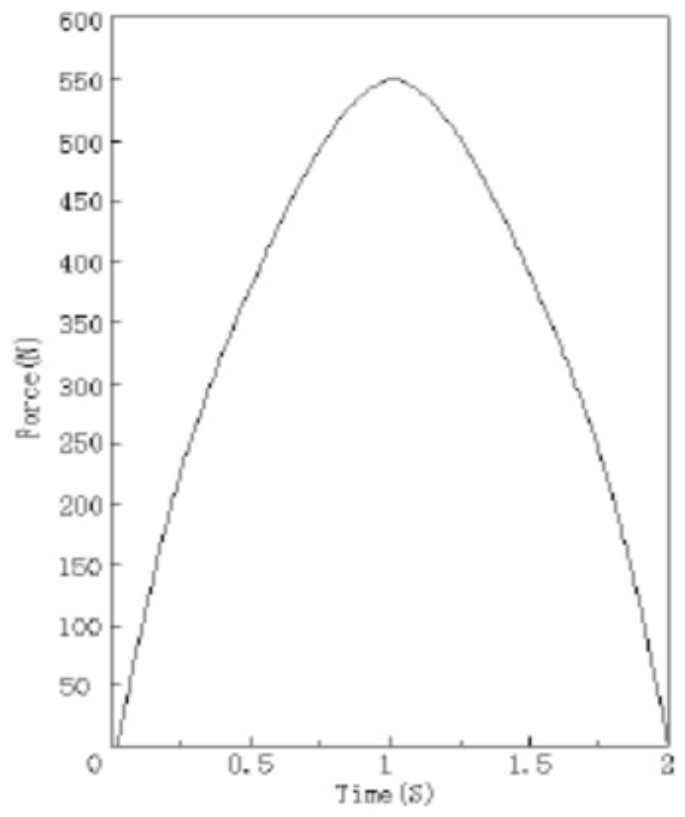

图 2 公交客车座椅载荷曲线 


\section{4 结构优化}

不断发展的汽车工业, 密度越来越高的公路, 使人们对出行质量提出的更高的要求, 其中, 应当引起重视的内容 为公交客车的舒适性、安全性。作为组成公交客车所不可或缺的一部分, 座椅的价值体现在提高客车舒适性、保护乘 客安全等方面。通过上文的分析可以看出, 优化公交客车结构的切入点, 主要有以下两点: 其一, 用屈服极限更高、 强度更高的钢材料, 对普通钢材料进行替换。增加横管厚度、提高材料屈服极限后, 通过优化连接块结构的方式, 提 高其安全性, 这是因为对座椅有效性进行评估的参考要素, 主要是连接块、连接部位。由于连接部位所受冲击载荷来 自多个方向, 因此, 在条件允许的前提下, 工作人员可对屈服极限进行提高, 一般来说, 被用于提高屈服极限的零部 件, 主要是加强板、加强筋, 其中, 前连接块可通过增加加强板的方式, 使屈服极限得到提高, 后连接块则更适合对 加强筋加以应用。其二, 极限载荷所带来冲击是导致连接块、座盆侧板失效的主要原因, 在优化车身结构时, 工作人 员应将增加逃生空间为出发点。将滑架卡装在固定座架两侧, 将螺栓安装在滑架立侧面, 利用手柄旋紧螺栓, 将其定 位在凹槽内, 保证凸楞与凹槽共同形成有 “锁死” 功能的卡装槽, 将固定架、缓冲拉簧安装在固定座架上。如果处于 行驶状态下的公交客车, 由于遭受撞击而变形, 受安全杆推动力影响, 座椅锁紧装置松开并后移, 经由凸楞、凹槽、 拉簧的缓冲，将乘客受到挤压、卡压的几率降到最低，为其人身安全提供保障。

\section{结论}

实验结果表明, 最早出现度劳破坏的部位、存在较大应力值的部位, 均为连接座椅零件的部位, 因此, 优化车身 结构的侧重点, 应当集中在调角器、座盆侧板连接等方面, 保证车体受到撞击时, 锁紧装置自动松开、座椅后移, 再 对材料进行优化，使其屈服极限得到提高，只有这样才能达到优化座椅强度的目的。

\section{[参考文献]}

[1] 赵东伟,王正超, 尹怀仙. 基于变密度法的城市客车车架拓扑优化设计 [J]. 客车技术与研究, 2019, 41 (04) : 1-3.

[2] 王文甲, 吴长风,沈剑云, 等. 客车骨架局部结构的多工况拓扑优化设计 [J]. 客车技术与研究, 2018, 40 (01) : 26-29.

[3] 王钰明,顾添翼, 戴其燕, 等. 基于改进响应面法的纯电动客车车身结构优化设计 [J]. 机械设计, 2019, 36 (1): 97-103.

作者简介: 金宏宇（1987.1-)，男，杭州电子科技大学，机械设计制造及其自动化，浙江吉利新能源商用车发展有限 公司，车身主管工程师，中级职称。 